\title{
Functionalisation of PLLA nanofiber scaffolds using a possible cooperative effect between collagen type I and BMP-2: impact on growth and osteogenic differentiation of human mesenchymal stem cells
}

\author{
Markus D. Schofer • Anne Veltum • \\ Christina Theisen • Fei Chen · Seema Agarwal • \\ Susanne Fuchs-Winkelmann • Jürgen R. J. Paletta \\ Received: 13 December 2010/Accepted: 7 May 2011/Published online: 22 May 2011 \\ (C) The Author(s) 2011. This article is published with open access at Springerlink.com
}

\begin{abstract}
Mesenchymal stem cell differentiation of osteoblasts is triggered by a series of signaling processes including integrin and bone morphogenetic protein (BMP), which therefore act in a cooperative manner. The aim of this study was to analyze whether these processes can be remodeled in an artificial poly-(L)-lactide acid (PLLA) based nanofiber scaffold. Matrices composed of PLLAcollagen type I or BMP-2 incorporated PLLA-collagen type I were seeded with human mesenchymal stem cells (hMSC) and cultivated over a period of 22 days, either under growth or osteoinductive conditions. During the course of culture, gene expression of alkaline phosphatase (ALP), osteocalcin (OC) and collagen I (COL-I) as well as Smad5 and focal adhesion kinase (FAK), two signal transduction molecules involved in BMP-2 or integrin signaling were analyzed. Furthermore, calcium and collagen I deposition, as well as cell densities and proliferation, were determined using fluorescence microscopy. The incorporation of BMP-2 into PLLA-collagen type I nanofibers resulted in a decrease in diameter as well as pore sizes of the scaffold. Mesenchymal stem cells showed better adherence and a reduced proliferation on BMPcontaining scaffolds. This was accompanied by an increase in gene expression of ALP, OC and COL-I. Furthermore the presence of BMP-2 resulted in an upregulation of FAK, while collagen had an impact on the gene expression of
\end{abstract}

M. D. Schofer · A. Veltum - C. Theisen - S. Fuchs-Winkelmann ·

J. R. J. Paletta ( $\bowtie)$

Department of Orthopedics, University Hospital of Marburg,

Baldingerstraße, 35043 Marburg, Germany

e-mail: paletta@med.uni-marburg.de

F. Chen - S. Agarwal

Department of Chemistry, University of Marburg,

Hans-Meerwein-Straße, 35032 Marburg, Germany
Smad5. Therefore these different strategies can be combined in order to enhance the osteoblast differentiation of hMSC on PLLA based nanofiber scaffold. By doing this, different signal transduction pathways seem to be up regulated.

\section{Introduction}

The reconstruction of large bony defects after injury or tumor resection often requires the use of bone substitution. In Europe 500,000 surgeries/year require bone graft material [1]. Therefore artificial scaffolds based on synthetic biomaterials such as metals, polymers, porous ceramics, hydroxyl apatite, collagen sponge or hydrogels, and composites have been developed [2-8].

Among them, scaffolds based on nanofibers or nanoscaffolds offer great advantages $[9,10]$. They are thought to mimic the extracellular matrix (ECM) [11-14] and allow the differentiation of human mesenchymal stem cells (hMSC) towards osteoblasts. However, this process depends on the chemical composition of the nanofibers.

In comparison to other $\alpha$-(hydroxyester)-based nanofibrous scaffolds, poly-(L)-lactide acid (PLLA) scaffolds supported the highest rate of proliferation of mesenchymal stem cells [15] with a tendency to higher cell densities $[16,17]$. However, an initial down regulation of genes associated with the osteoblast linage $[16,18]$ can be observed on PLLA nanofibers. This effect can be eliminated by functionalisation of the nanofibers either by blending with collagen type I [19] or the incorporation by recombinant bone morphogenic protein 2 (BMP-2) [16]. Both strategies enhanced the differentiation of mesenchymal stem cells towards osteoblasts. In terms of collagen it is known that the adhesion to collagen I (COL-I) via the 
$\alpha 2 \beta 1$ integrin is sufficient to induce osteogenic differentiation of hMSC's, even in the absence of exogenous stimuli $[20,21]$. BMP-2 induces different factors involved in the differentiation of hMSC towards osteoblasts [22-31] and is necessary to induce bone formation [32-34]. Furthermore BMP-2 induces the formation of $\alpha \mathrm{v} \beta$-Integrin on osteoblasts $[35,36]$. These, in interaction with the ECM, influences the BMP-function [36] resulting in migration, activation of focal adherence kinase and formation of focal adhesion [37, 38]. Suzawa et al. [39] found evidence, that the downstream pathway of integrin is involved in Smad1 signals activated by BMP-2 and provide a possible mechanism for cooperation between intracellular signals activated by integrin and BMP receptors in osteoblastic cells.

In order to analyze whether this cooperative effect can be utilized in PLLA nanofiber based bone replacement material we constructed BMP-2 containing PLLA-collagen type I blended nanofiber scaffolds and analyzed their ability to induce osteoblast differentiation of hMSC.

\section{Materials and methods}

\subsection{Construction of nanofibers and characterization}

The preparation of PLLA and PLLA-collagen type I blend nanofibers as well as the incorporation of BMP-2 into PLLA nanofibers by electrospinning has been reported in detail earlier $[16,19,40]$. Briefly, a 4\% (w/w) PLLA (Resomer L210, Boeringer Ingelheim Germany) solution in dichloromethane (DCM) was prepared at room temperature by stirring overnight until a homogenous solution was obtained. Spinning process was performed at a flow rate of $14 \mu \mathrm{l} / \mathrm{min}$ with an applied voltage of $20-30 \mathrm{kV}$ and a distance of $15 \mathrm{~cm}$. The spinning solution had a surface tension of $28.34 \pm 0.03 \mathrm{mN} / \mathrm{m}$, a viscosity of $1.561 \mathrm{PaS}$ and a conductivity of $\sim 0 \mu \mathrm{s} / \mathrm{cm}$. Samples of non woven PLLA nanofibers were fixed on $18 \mathrm{~mm}$ cover slips for cell culture experiments.

To incorporate collagen type I into the nanofibers, PLLA and collagen were dissolved in hexafluoroisopropanol (HFIP) in a $4: 1$ ratio resulting in a $4.5 \%(\mathrm{w} / \mathrm{v})$ polymer solution. Here the spinning solution had a surface tension of $18.33 \pm 0.03 \mathrm{mN} / \mathrm{m}$, a viscosity of $1.529 \mathrm{PaS}$ and a conductivity of $\sim 4.7 \mu \mathrm{s} / \mathrm{cm}$. Spinning process was performed at a flow rate of $14 \mu \mathrm{l} / \mathrm{min}$ with an applied voltage of $10-18 \mathrm{kV}$ and a distance of $15 \mathrm{~cm}$.

In order to incorporate BMP-2 into the nanofibers, $25 \mu \mathrm{g}$ lyophilized BMP-2 (Reliatech, Braunschweig Germany) was dissolved in $125 \mu \mathrm{l} 50 \mathrm{mM}$ acetic acid and stabilized by the addition of $25 \mu \mathrm{l}$ fetal calf serum (FCS). This mixture was emulsified in $2.5 \mathrm{ml}$ of a $4.5 \%$ PLLA-collagen type I solution (4:1) over a period of $1 \mathrm{~min}$ using a vortex mixer (MS 2 Minishaker IKA $^{\circledR} ; 2,500 \mathrm{rpm}$ ). This solution was sufficient for the spinning of 50 cover slips with BMP-2 depending on the spinning and fiber collection process. Spinning process was performed at a flow rate of $14 \mu \mathrm{l} / \mathrm{min}$ with an applied voltage of $10-18 \mathrm{kV}$ and a distance of $15 \mathrm{~cm}$. In some experiments BMP was replaced by a fluoresceinisothiocyanat (FITC)-labeled protein, to analyze the distribution within the nanofibers and release of growth factors form the PLLA Collagen fibers.

\subsection{Pore size distribution}

The pore size distribution of the three electrospun scaffold was determined using a capillary flow porometer (type: CFP1200-AEXL, Porous Materials Inc., USA). A wetting liquid, Galwick $^{\mathrm{TM}}$ (Porous Materials Inc., USA) was applied to spontaneously fill the pores in the scaffold and differential pressure of nitrogen gas was slowly increased on the sample to remove the liquid within the pores and permit gas flow. The differential pressure and flow rates through dry and wet scaffold were measured. All the required pore structure characteristics such as pore size at bubble point mean flow pore and pore size distribution were computed from the measured differential pressures and gas flow rates [41].

\subsection{Scanning electron microscopy}

For scanning electron microscopy (SEM), samples were sputter-coated with gold in an AUTO-306 (BOC Edwards, Crawley, Sussex, U.K.) high-vacuum coating system and examined in a SEM (S-4100, Hitachi Ltd., Tokyo, Japan) at an accelerating voltage of $5 \mathrm{kV}$ in the SE mode.

\subsection{Human mesenchymal stem cell isolation, characterization and culture}

HMSC cells were obtained from consenting patients with the approval of the institutional review board. The indication for surgery was primary osteoarthritis of the hip. The patients had no evidence of other bone or auto immune diseases. The routinely removed bone was obtained from the proximal femur, while preparing the implant bed. HMSC were isolated and cultured according to the preparation of Pittenger et al. [42], with minor modification as described by Brendel et al. [43].

Within the experiments, hMSCs preparations negative for CD34 and CD40 and positive for the stem cell markers CD90 and CD105 were used. In order to ensure the osteoinductive potential of the obtained cells, gene expression of alkaline phosphatase (ALP), in response to dexamethasone, was determined prior to the experiments.

For experiments, hMSC were seeded at a density of $3 \times 10^{4}$ cells $/ \mathrm{cm}^{2}$ on cover slips or cover slips coated with nanofibers in growth medium (DMEM), with low glucose and glutamine (PAA, Linz, Austria) supplemented with 
$10 \%$ fetal calf serum (FCS) from selected lots (Biochrom, Berlin, Germany) and $1 \%$ penicillin/streptomycin. Osteogenic differentiation was induced according to Jaiswal et al. [44] after an initial proliferation phase of 3 days. The medium was replaced every second day of culture.

\subsection{Gene expression analysis}

RNA was extracted from cell layers at days 2, 4, 10 and 22 (after introduction of osteoinductive conditions) using Peq Gold total RNA Kit (PeqLab, Erlangen, Germany) according to the manufacturer and quantified spectrometrically. Starting from $1 \mu \mathrm{g}$ RNA, $20 \mu \mathrm{l}$ cDNA were synthesized using Verso cDNA Kit (Thermo Fisher Scientific, Lafayette, USA) with oligo-dT primer in the presence of dNTP. Quantitative RT-PCR reactions were performed and monitored using a Mastercycler ${ }^{\circledR}$ ep realplex Detection System (Eppendorf, Hamburg, Germany) and Absolute Blue QPCR Sybr Green Mix (Thermo Fisher Scientific, Lafayette, USA). Genes of interest were analyzed in cDNA samples ( $5 \mu \mathrm{l}$ for a total volume of $50 \mu \mathrm{l} /$ reaction) using DeltaDeltaCt method and CyberGreen. Primers (purchased at TIB Biomol, Berlin, Germany), cycle temperatures and incubation times for human alkaline phosphatase (ALP), collagen I (COL-I), osteocalcin (OC), and $18 \mathrm{~s}$ rRNA were previously described [45-47]. The primer sequence for focal adhesion kinase (FAK) was $5^{\prime}$ ACC TCA GCT AGT GAC GTA TGG $-3^{\prime}$ and $5^{\prime}$ CGG AGT CCC AGG ACA CTG TG $3^{\prime}$ (gen bank L0518666), PCR Primers for Smad5 were obtained ready to use form www.realtimeprimers.com.

\subsection{Immunofluorescence microscopy}

Samples were fixed in acetone/methanol, washed with PBS $(3 \times)$, and exposed to blocking buffer (1\% donkey serum albumin PBS) over a period of $30 \mathrm{~min}$ at room temperature to minimize non-specific absorption of the antibodies. After another wash in PBS $(3 \times)$, the cells were incubated with primary antibodies against COL-I (Abcam, Ab6308, Cambridge, United Kingdom), OC (Acris, BP710, Hiddenhausen, Germany), Ki-67 (Darko, Hamburg, Germany) FAK (BD Biosciences, San Jose, California, USA) and Smad5 (Santa Cruz Biotechnology, Inc. Heidelberg, Germany). Visualization was done, after washing in PBS $(3 \times)$ using cy-2- or cy-3-conjugated secondary antibody (Dianova, Hamburg, Germany) at room temperature (1 h). The slices were stained with DAPI and embedded in mounting medium. Fluorescence microscopy was done using a Leica DM5000. Microphotographs of at least three different areas were made and intensity of fluorescence was determined using Quips analysis software. Total cell count of DAPI stained nuclei were obtained. Patient series were analyzed by independent observers.

\subsection{Detection of calcium deposition}

Von Kossa staining was performed using $1 \%$ aqueous silver nitrate solution for $1 \mathrm{~h}$ followed by several washing steps in distilled water and incubation in 5\% sodium thiosulfate for $5 \mathrm{~min}$. Alizarin red staining was performed using $2 \mathrm{~g} / 100 \mathrm{ml}$ at $\mathrm{pH} 4.1-4.3$.

\subsection{Statistics}

All values were expressed as mean \pm standard error of at least three different patients and compared using student's $t$-test or ANOVA with Bonferroni as a post hoc test. Values of $P<0.05$ were considered to be significant. Significant values were marked with *.

\section{Results}

3.1 Characterization of PLLA collagen blend nanofibers with or without BMP-2 incorporation

Scanning electron microscopy of electrospun PLLA nanofibers revealed a 3-D non-woven network with a diameter of $0.775 \pm 0.294 \mu \mathrm{m}$. Fibers were porous in structure. The PLLA-collagen type I blend nanofibers revealed a 3-D non-woven network with a diameter of $0.421 \pm 0.023 \mu \mathrm{m}$ for the blend (Fig. 1c). The PLLA-collagen type I blend nanofibers presented themselves with a relatively smooth surface (Fig. 1a). The pore size of the resulting scaffolds was about $2 \mu \mathrm{m}$ as demonstrated in Fig. 1d.

The incorporation of BMP-2 into these fibers reduced the diameter to $0.217 \pm 0.009 \mu \mathrm{m}$ and resulted in a smaller pore size (approximately $0.6 \mu \mathrm{m}$ ) as shown in Fig. $1 \mathrm{~b}$ and c. When FITC labelled bovine serum albumin (BSA) was used as a model for the incorporation of proteins by electrospinning, fluorescence microscopy showed evidence that the dye was distributed uniformly within the fibers (Fig. 2a). When these fibers were incubated in phosphate buffer at $37^{\circ} \mathrm{C}$, the fluorescence remained within the fiber over a period of 14 days (Fig. 2b). Nevertheless the sharpness of the fibers becomes indistinct. Correspondingly using UV-visible-spectroscopy, no time dependent release could be detected (data not shown).

\subsection{Adhesion of mesenchymal stem cells on nanofiber scaffolds}

In order to describe the biological effects of blending PLLA with collagen as well as the incorporation of BMP-2 into PLLA-collagen type I blend nanofibers, we first analyzed the adhesion of hMSC on the desired scaffolds. Cells were seeded on the scaffolds and allowed to adhere over a period of $12 \mathrm{~h}$. As shown in Fig. 3, during this time, 

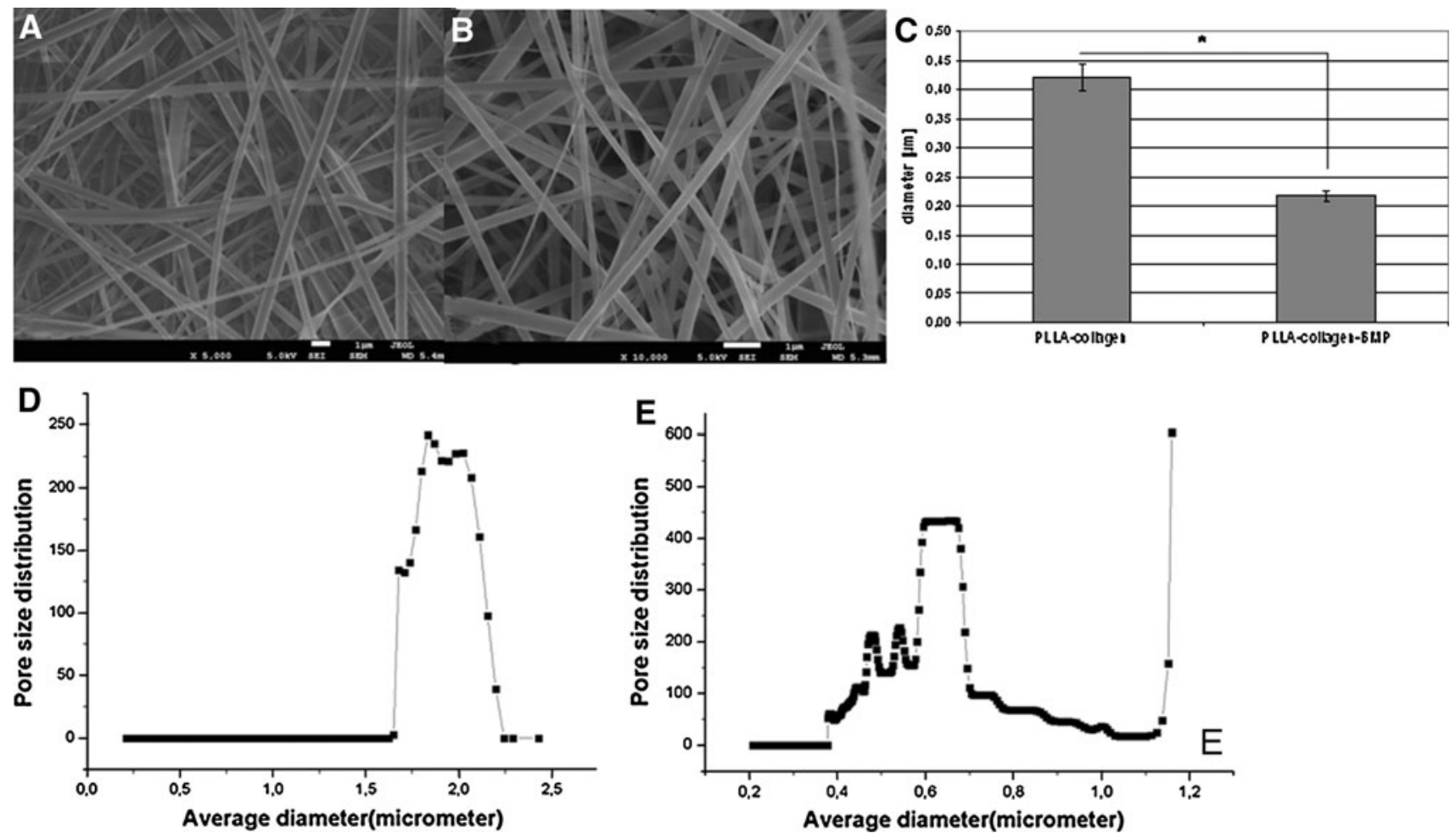

Fig. 1 Fiber characterization. SEM analysis of PLLA-collagen blend (a) and BMP-2 enwoved PLLA-collagen blend nanofibers (b) and the resulting fiber diameters (c) and pore sizes of the PLLA-collagen blend (d) and BMP-2 enwoved PLLA-collagen blend nanofibers (e)
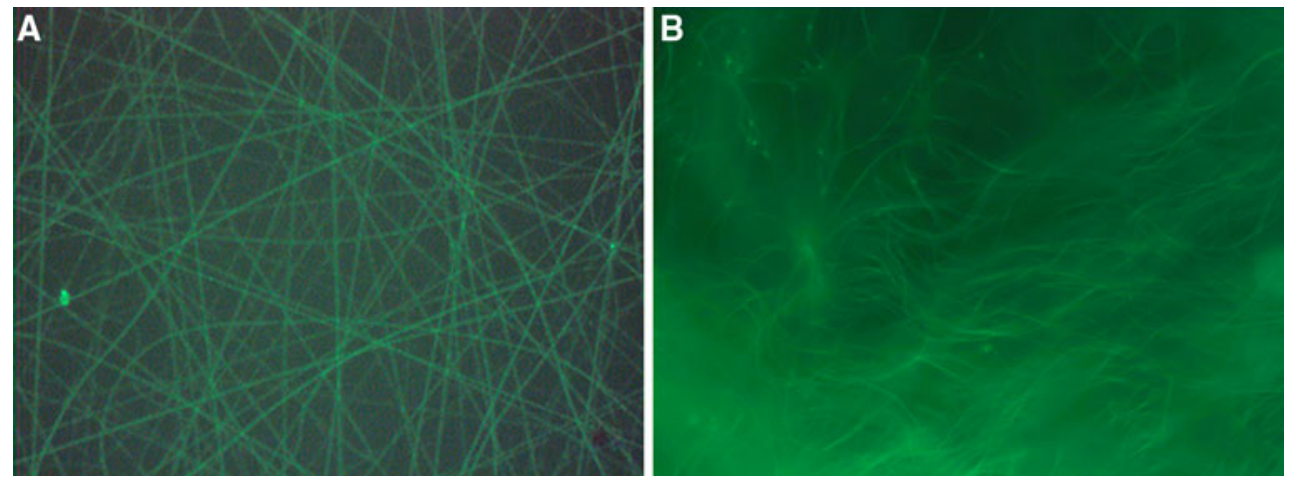

Fig. 2 Release characteristics of BMP-2 enwoved PLLA-collagen blend nanofibers. Fluorescence microscopy analysis of BMP-2 enwoved PLLA-collagen blend nanofibers after incubation in aquarius solutions over a period of 1 (a) and 14 days (b)

approximately three times more cells adhered on PLLAcollagen type I blend nanofibers. Nevertheless, this effect was not significant at all. The incorporation of BMP-2 into the PLLA-collagen type I blend scaffolds resulted in a four to five fold increase $(p=0.044)$.

\subsection{Growth and proliferation of human hMSC cultured on nanofibers}

Focusing on growth of hMSC, we next cultured the cells over a period of 22 days on PLLA, PLLA-collagen type I, and PLLA-collagen type I nanofiber scaffolds containing BMP-2. Under growth conditions significant differences between cell densities between PLLA and PLLA-collagen type I $(p=0.000)$ as well as PLLA-collagen type I containing BMP-2 $(p=0.015)$ were found after 22 days (Fig. 4a).

Under osteoinductive conditions after 4 days of culture significance was reached (PLLA/PLLA-collagen nanofibers $P=0.001$; PLLA-collagen nanofibers containing BMP-2 $(p=0.000))$. In case of PLLA-collagen nanofibers significant higher cell densities were found over the time 


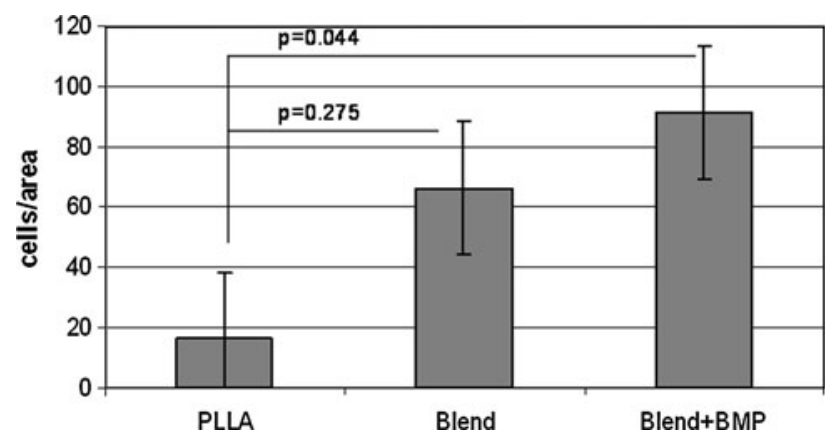

Fig. 3 Influence of PLLA, PLLA-collagen blend and BMP-2 containing PLLA-collagen blend nanofibers on adhesion
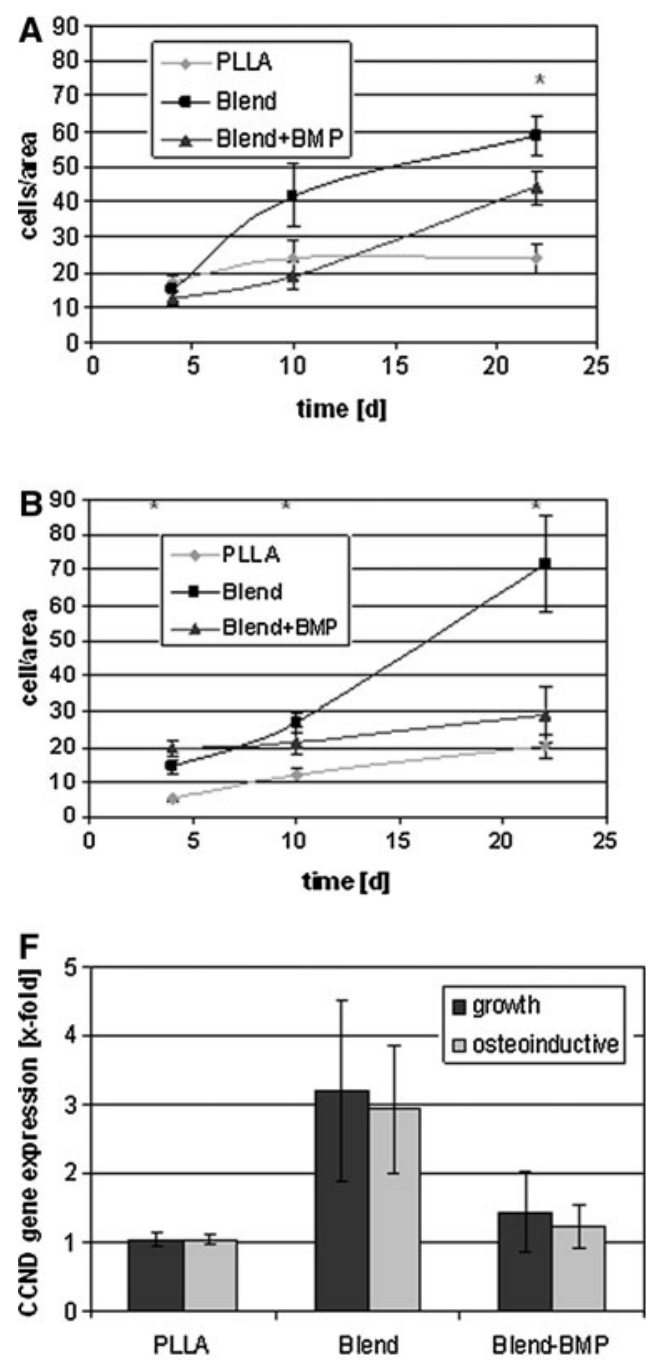

Fig. 4 Influence of PLLA, PLLA-collagen blend and BMP-2 containing PLLA-collagen nanofibers on growth and proliferation of hMSC cultured under growth and osteoinductive conditions. Time course of cell densities cultured under growth (a) and osteoinductive course of the experiment as compared to PLLA nanofibers (day $10, P=0.004$; day $22, P=0.003$ ). At these time points no significant differences between PLLA and PLLAcollagen type I nanofibers containing BMP-2 were detected (Fig. 4b). This growth pattern was reflected in the gene expression of Cyclin 1D (CCND) normalized to $18 \mathrm{~s}$. Here the gene expression was increased when cells were cultured on PLLA-collagen type I blend nanofibers as compared to PLLA nanofibers. Furthermore the presence of BMP-2 resulted in a reduced CCND gene expression (Fig. 4f). Consequently this pattern could be detected using Ki67 staining (Fig. 4c, d, e).
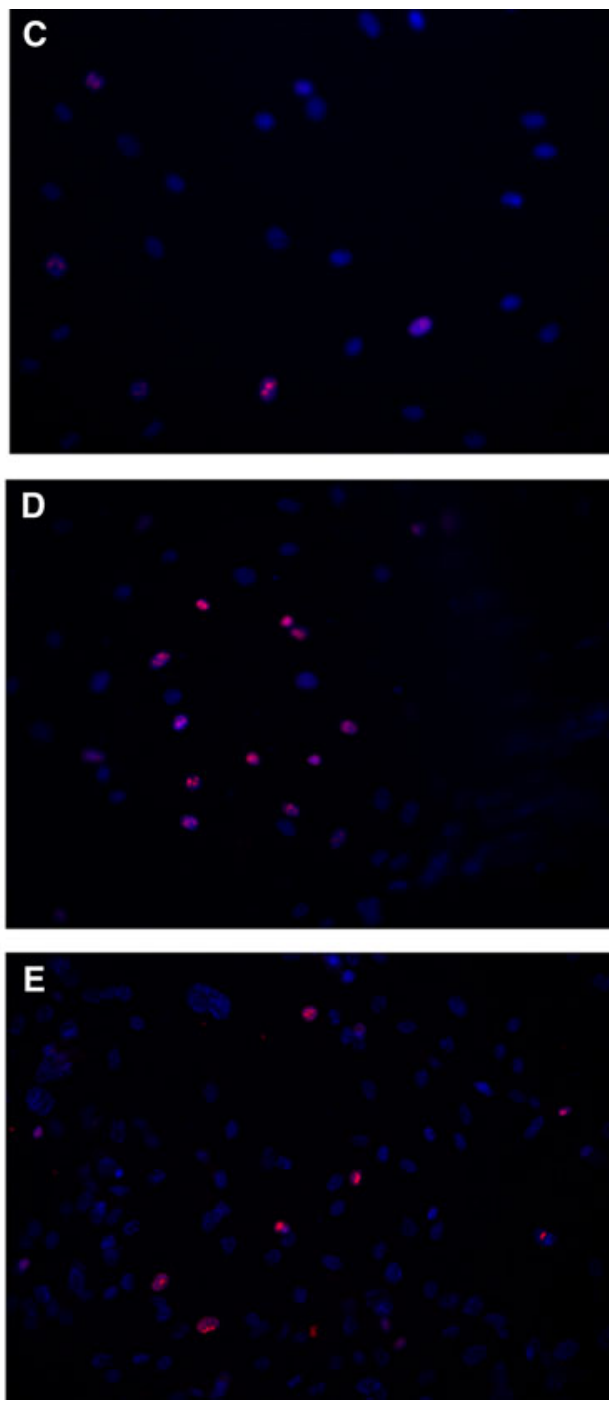

proliferation as determined by Ki67 staining of hMSC cultured under osteoinductive conditions on cover PLLA nanofibers (c), PLLAcollagen blend nanofibers (d) and BMP-2 enwoved PLLA-collagen blend nanofibers (e). Gene expression of CCND after 4 days of cell culture as compared to PLLA (f) 


\subsection{Influence of PLLA-nanofibers}

on the differentiation and matrix formation of hMSC

To examine the influence of incorporation of BMP-2 into PLLA-collagen type I on hMSC differentiation into osteoblasts we compared the gene expression of alkaline phosphatase, collagen type-I and osteocalcin of cells, grown on PLLA-collagen type I blend nanofibers with or without BMP-2. Although there was a broad inter-assay variability (mainly responsible for the lack of significance) the presence of BMP-2 resulted in an increase of alkaline phosphatase and osteocalcin (Fig. 5a, b). The reason why osteocalcin and alkaline phosphatase expression was increased in the early stage and decreased during the time course is due to the ddCT method used to compare expression between the scaffolds at each time point and not in a time dependent manor. Here von Kossa as well as alizarin staining gave evidence that osteogenesis was more dominant when cells were cultured under osteoinductive conditions. Furthermore when BMP was incorporated this effect seems to be enhanced (Fig. 5c).

This was accompanied by a significant increase in the gene expression of collagen type I (Fig. 6a) when cells were cultured on BMP-2 containing nanofiber scaffolds as compared to PLLA-collagen nanofibers alone. This effect was independent from culture conditions and resulted in an enhanced deposition of the corresponding proteins in the nanofiber scaffolds over a period of 22 days as demonstrated by immunofluorescence (Fig. 6b, c, d, e).

\subsection{Influence of nanofiber composition signal transduction}

Because collagen blended PLLA nanofibers [19] as well as BMP-2 containing PLLA nanofibers [16] enhance the differentiation of mesenchymal stem cells towards osteoblasts
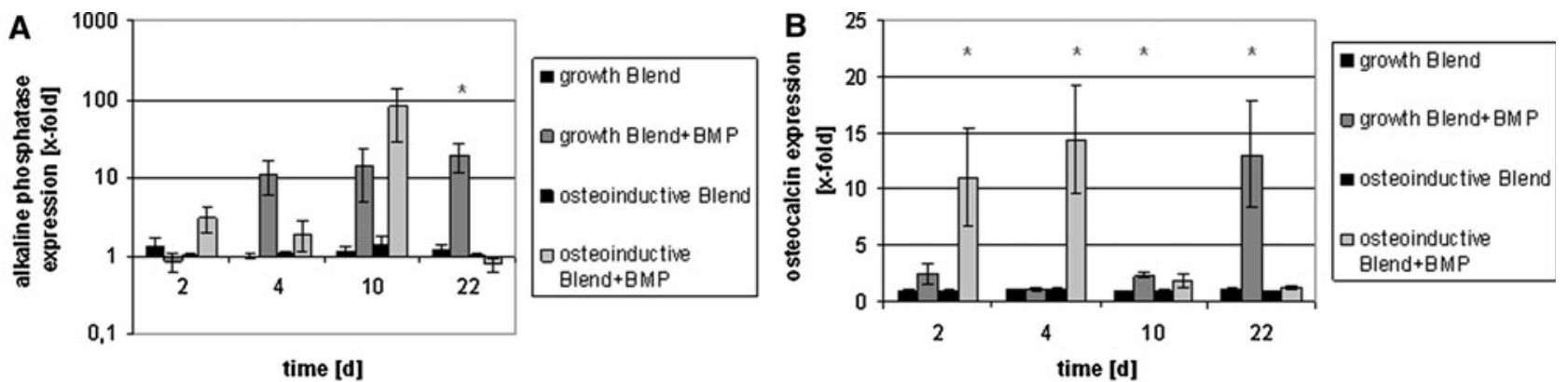

C
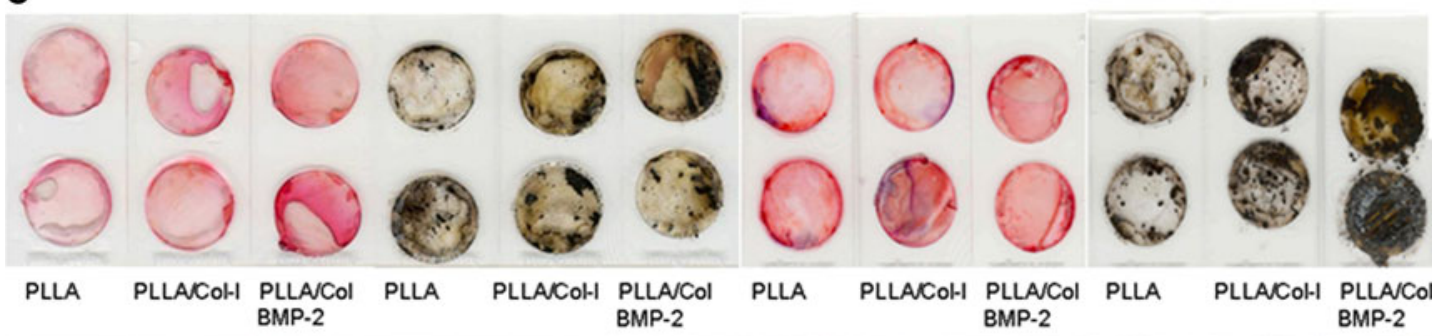

osteoinductive conditions

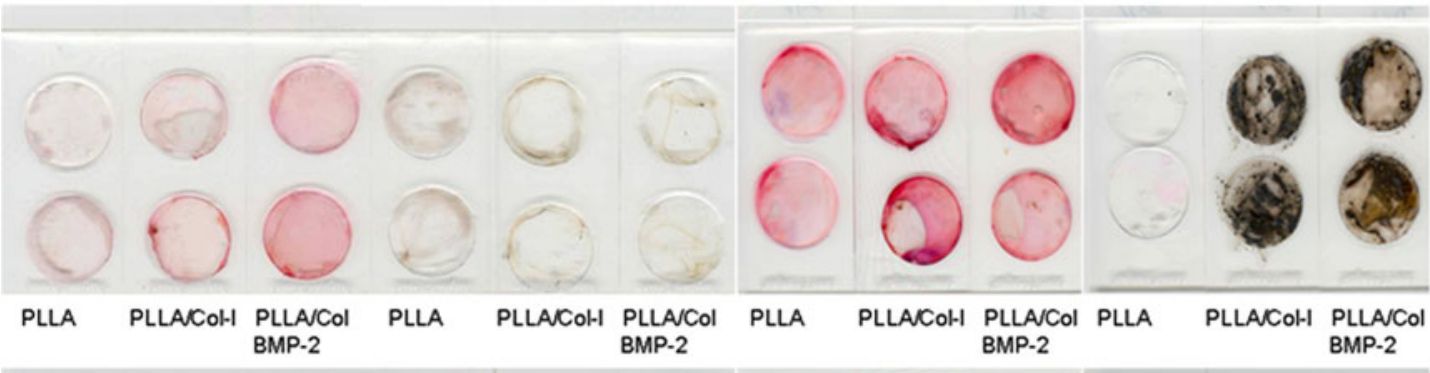

growth conditions

\section{day 10 of incubation}

Fig. 5 Influence of BMP-2 containing PLLA-collagen blend nanofibers on differentiation of hMSC towards osteoblasts cultured under growth and osteoinductive conditions. Time course of alkaline phosphatase (a) and osteocalcin (b) gene expression of hMSC cultured under growth and osteoinductive conditions on BMP-2 day 22 of incubation

containing PLLA-collagen blend nanofibers compared to PLLAcollagen blend nanofibers without BMP. c Alizarin (red) and von Kossa staining (Black) of hMSC cultured under growth and osteoinductive conditions on different nanofiber scaffolds (Color figure online) 

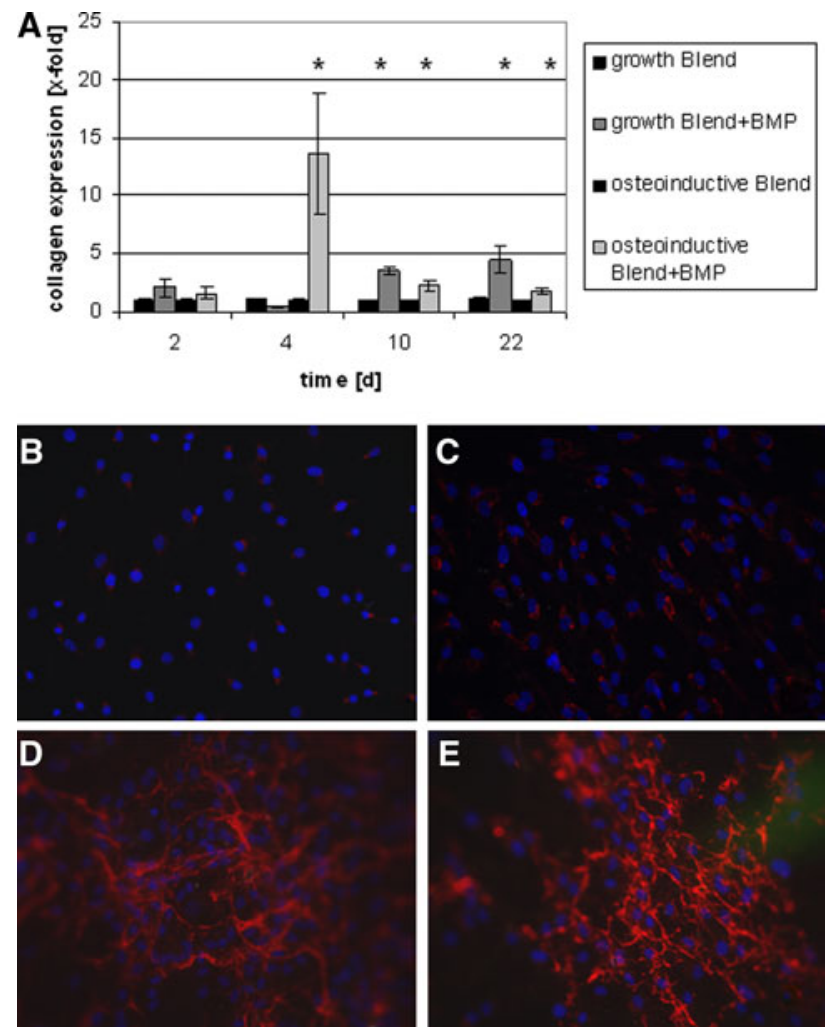

Fig. 6 Influence of PLLA-collagen blend nanofibers and BMP-2 containing PLLA-collagen blend nanofibers on collagen type-I gene expression and matrix deposition of hMSC cultured under growth and osteoinductive conditions. Time course of gene expression of hMSC cultured under growth and osteoinductive conditions (a). Immunofluorescence microphotographs of COL-I (red) deposition after 22 days of culture on PLLA-collagen blend nanofibers (b) BMP-2 containing PLLA-collagen blend nanofibers under growth conditions (c) or osteoinductive conditions $(\mathbf{d}, \mathbf{e})$

and additionally integrin activation by collagen was involved in BMP signals in osteoblastic MC3T3-E1 cells [39] we next analyzed the occurrence of FAK and Samd5 (which are key regulator molecules in the corresponding pathways) using real time PCR and fluorescence microscopy. As compared to PLLA nanofibers alone, the PLLA collagen type I nanofibers showed an increased expression gene of the FAK gene (Fig. 7) which resulted in an increase of FAK within the cells. This effect was boosted when BMP2 was incorporated into the PLLA collagen type I nanofibers. Similar findings were made with respect to Smad5 (Fig. 8), although the elicited effects by BMP-2 were two times higher as compared to FAK gene expression.

\section{Discussion}

Tissue-engineering scaffolds should be analogous to native ECM in terms of both chemical composition and physical
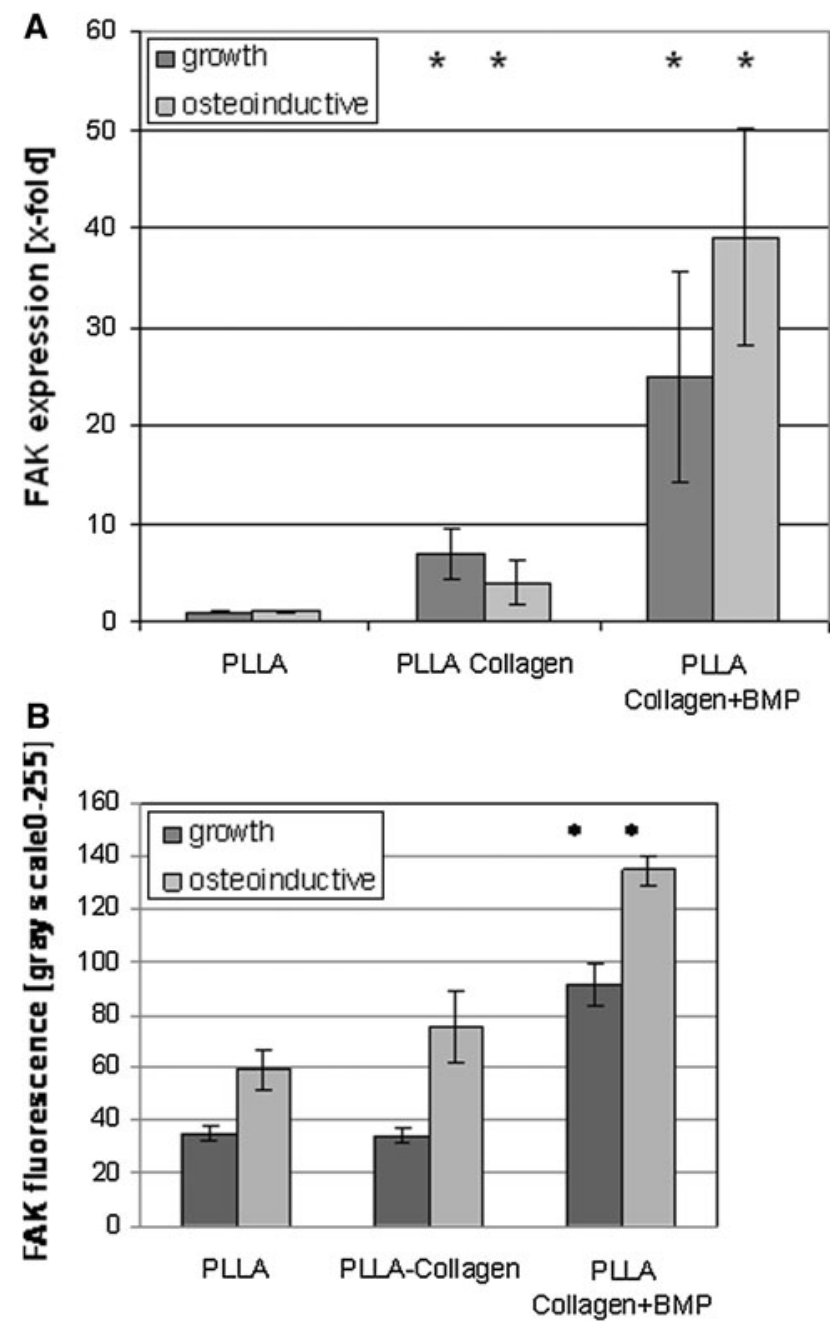

Fig. 7 Influence of PLLA-collagen blend nanofibers and BMP-2 containing PLLA-collagen blend nanofibers on FAK gene expression and immunofluorescence detection of FAK in hMSC cultured under growth and osteoinductive conditions

structure. Polymeric nanofiber matrix, with its nanoscaled nonwoven fibrous structure is a candidate for ECMmimetic material [48]. Besides the structural effects (elicited by the nanofibers) signals mediated by growth factors and/or collagen sequences like RGD-integrin system are important to develop artificial tissue. In case of bone regeneration, members of the TGF- $\beta$ superfamily, the bone morphogenetic proteins are necessary [28-31]. We demonstrated earlier that the incorporation of BMP-2 into PLLA nanofiber scaffolds by electrospinning is useful to enhance the osteoblastic differentiation of hMSC as determined by an increased gene expression of genes associated with the osteoblast [16]. Furthermore it was shown, that BMP-2 induces the formation of $\alpha \mathrm{v} \beta$-integrins on osteoblasts $[35,36]$. These-in interaction with the ECM-influence the BMP-2 function [36]. Beyond that, 

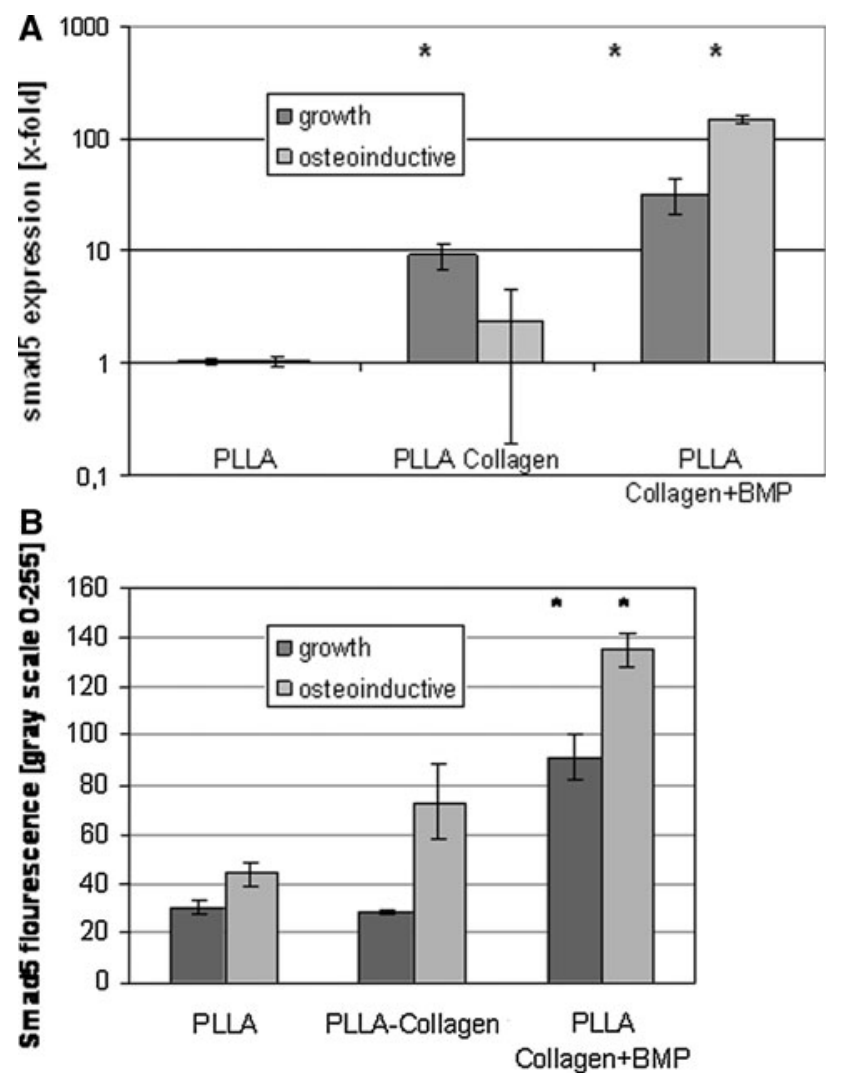

Fig. 8 Influence of PLLA-collagen blend nanofibers and BMP-2 containing PLLA-collagen blend nanofibers on Smad5 gene expression and immunofluorescence detection of smad5 in hMSC cultured under growth and osteoinductive conditions

the adhesion to collagen via the $\alpha 2 \beta 1$ integrin is sufficient to induce osteogenic differentiation of hMSC's, even in the absence of exogenous stimuli [20, 21]. Indeed, this property is carried to collagen nanofiber scaffolds $[18,49]$ as well as nanofiber scaffolds form other polymers, blended with collagen $[19,50]$.

Within this paper we analyzed whether the combination of both stimuli (BMP-2 and collagen) have a cooperative effect when incorporated into PLLA nanofibers.

With respect to adhesion, the BMP incorporation into PLLA-collagen type I nanofibers resulted in an increased adhesion of hMSC on the nanofibers. Although we cannot exclude that the differences in pore size or fiber diameter were involved in this phenomenon, we speculate, that upregulation of integrins by BMP-2 [35, 36] could be responsible for this effect. This speculation is supported by the finding that cells cultured on this fiber type possess higher gene expression levels as well as protein levels of focal adhesion kinase, a key regulator of the integrin signaling pathway. However additional studies are necessary to support this speculation.

As reported earlier, the collagen nanofiber scaffold increased cell densities [19] as well as proliferation.
The additional incorporation of BMP-2 resulted in a reduced proliferation and lower cell densities. This can be explained by the osteoinductive stimulus elicited by BMP2. In fact we found an increased gene expression of alkaline phosphatase and osteocalcin, marker of osteoblast differentiation. Furthermore this speculation is supported by an upregulation of Smad5 which is involved in the BMP-2 signal transduction pathway. In addition, this effect was enhanced when osteoinductive conditions were applied. The latter finding is in accordance with cooperative effects between dexamethason and BMP-2 on hMSC differentiation [51]. Taken together this indicates that BMP-2 and not the altered fiber size is responsible for the biological effects on hMSC. Therefore our study indicates that the nanofiber scaffolds can be used to combine the activation of different signal transduction pathways. This facilitates the use of cooperative effects-at least in the differentiation of hMSC towards osteoblasts.

Whether this is sufficient for a bone replacement material, depends although on physical prosperities of the scaffold. The design of scaffolds for bone tissue engineering is based on the physical properties of bone tissue such as mechanical strength, pore size, porosity, hardness, overall 3D architecture and-when used as a drug carrier system - the presentation of the growth factor. Although PLLA is known to possess poor protein release properties [52, 53], during electro-spinning process hydrophilic compounds were accumulated on the fiber surface [54]. The large surface and the porous structure of PLLA nanofibers, might facilitate contact to the BMP-2 receptor of the growing cell and elicit differentiation [16]. In case blend nanofibers similar behavior can be expected. The latter showed that the growth factor was detectable by fluorescence microscopy over a period of 14 days. Although the blend fibers formed a gel-like structure over time, which was observed earlier in unfixed collagen blended nanofibers [19], this effect had no impact on the release kinetics of the incorporated BMP-2. This might be explained by the collagen binding sequence, presented in BMP-2 [55, 56], retarding the growth factor without detectable effect on the BMP-bioavailability. Maybe this form of BMP-2 presentation is similar to the extra cellular matrix, facilitating the BMP-2 contact to its receptors.

More problematic might be the pore size of the nanofiber scaffolds. For bone tissue engineering, scaffolds with a pore size in the range of $100-350 \mu \mathrm{m}$ are preferred for better cell/tissue in-growth and hence enhanced bone regeneration [57, 58]. Here the PLLA-collagen type I as well as the BMP-2 enwoved PLLA-collagen I nanofiber scaffolds show some disadvantages concerning their pore size. Whether this might be compensated by the formation of the gel like structure, or the degradation of collagen after implantation has to be analyzed in vivo. 


\section{Conclusion}

It has been shown earlier that PLLA nanofiber scaffolds can be functionalized by either growth factors or components from the ECM. Here we demonstrated that these different strategies can be combined in order to enhance the osteoblast differentiation of hMSC. By doing this, different signal transduction pathways seemed to be up regulated.

Open Access This article is distributed under the terms of the Creative Commons Attribution Noncommercial License which permits any noncommercial use, distribution, and reproduction in any medium, provided the original author(s) and source are credited.

\section{References}

1. Wirth CJ, Windhagen $\mathrm{H}$. New technologies in tissue engineering. Visions of an unlimited bone generation without problems. Orthopade. 2004;33:1335-7.

2. Agarwal S, Wendorff JH, Greiner A. Use of electrospinning technique for biomedical applications. Polymer. 2008;49: 5603-21.

3. Glowacki J, Mizuno S. Collagen scaffolds for tissue engineering. Biopolymers. 2008;89:338-44.

4. Roberts SJ, Howard D, Buttery LD, Shakesheff KM. Clinical applications of musculoskeletal tissue engineering. $\mathrm{Br}$ Med Bull. 2008;86:7-22.

5. Silva GA, Coutinho OP, Ducheyne P, Reis RL. Materials in particulate form for tissue engineering. 2. Applications in bone. J Tissue Eng Regen Med. 2007;1:97-109.

6. Shin H, Temenoff JS, Bowden GC, Zygourakis K, Farach-Carson MC, Yaszemski MJ, Mikos AG. Osteogenic differentiation of rat bone marrow stromal cells cultured on Arg-Gly-Asp modified hydrogels without dexamethasone and beta-glycerol phosphate. Biomaterials. 2005;26:3645-54.

7. Khan Y, Yaszemski MJ, Mikos AG, Laurencin CT. Tissue engineering of bone: material and matrix considerations. J Bone Joint Surg Am. 2008;90(Suppl 1):36-42.

8. Kneser U, Schaefer DJ, Polykandriotis E, Horch RE. Tissue engineering of bone: the reconstructive surgeon's point of view. J Cell Mol Med. 2006;10:7-19.

9. Ashammakhi N, Ndreu A, Yang Y, Ylikauppila H, Nikkola L. Nanofiber-based scaffolds for tissue engineering. Eur J Plast Surg, online first. 2008.

10. Zhang Y, Lim CT, Ramakrishna S, Huang ZM. Recent development of polymer nanofibers for biomedical and biotechnological applications. J Mater Sci Mater Med. 2005;16:933-46.

11. Li WJ, Laurencin CT, Caterson EJ, Tuan RS, Ko FK. Electrospun nanofibrous structure: a novel scaffold for tissue engineering. J Biomed Mater Res. 2002;60:613-21.

12. Liao S, Li B, Ma Z, Wei H, Chan C, Ramakrishna S. Biomimetic electrospun nanofibers for tissue regeneration. J Biomed Mater. 2006; $1:$ R45-53.

13. Ruiyun Zhang PXM. Synthetic nano-fibrillar extracellular matrices with predesigned macroporous architectures. J Biomed Mater Res. 2000;52:430-8.

14. Woo KM, Jun J-H, Chen VJ, Seo J, Baek J-H, Ryoo H-M, Kim G-S, Somerman MJ, Ma PX. Nano-fibrous scaffolding promotes osteoblast differentiation and biomineralization. Biomaterials. 2007;28:335-43.

15. Li WJ, Cooper JA Jr, Mauck RL, Tuan RS. Fabrication and characterization of six electrospun poly(alpha-hydroxy ester)- based fibrous scaffolds for tissue engineering applications. Acta Biomater. 2006;2:377-85.

16. Schofer MD, Fuchs-Winkelmann S, Gräbedünkel C, Wack C, Dersch R, Rudisile M, Wendorff JH, Greiner A, Paletta JRJ, Boudriot U. Influence of poly(L-Lactic Acid) nanofibers and Bmp-2-containing poly(L-Lactic Acid) nanofibers on growth and osteogenic differentiation of human mesenchymal stem cells. Sci World J. 2008;8:1269-79.

17. Badami AS, Kreke MR, Thompson MS, Riffle JS, Goldstein AS. Effect of fiber diameter on spreading, proliferation, and differentiation of osteoblastic cells on electrospun poly(lactic acid) substrates. Biomaterials. 2006;27:596-606.

18. Schofer MD, Boudriot U, Wack C, Leifeld I, Gräbedünkel C, Dersch R, Rudisile M, Wendorff HJ, Greiner A, Paletta JRJ, Fuchs-Winkelmann S. Influence of nanofibers on the growth and osteogenic differentiation of stem cells-a comparison of biological collagen nanofibers and synthetic plla fibers. J Mater Sci Mater Med. 2008;20:767-74.

19. Schofer MD, Boudriot U, Leifeld I, Sutterlin RI, Rudisile M, Wendorff JH, Greiner A, Paletta JR, Fuchs-Winkelmann S. Characterization of a plla-collagen i blend nanofiber scaffold with respect to growth and osteogenic differentiation of human mesenchymal stem cells. Sci World J. 2009;9:118-29.

20. Salasznyk RM, Williams WA, Boskey A, Batorsky A, Plopper GE. Adhesion to vitronectin and collagen I promotes osteogenic differentiation of human mesenchymal stem cells. J Biomed Biotechnol. 2004; 24-34.

21. Mizuno M, Kuboki Y. Osteoblast-related gene expression of bone marrow cells during the osteoblastic differentiation induced by type I collagen. J Biochem. 2001;129:133-8.

22. Cheng S, Shao J, Charlton-Kachigian N, Loewy A, Towler D. Msx2 promotes osteogenesis and suppresses adipogenic differentiation of multipotent mesenchymal progenitors. J Biol Chem. 2003;278:45969-77.

23. Komori T, Yagi H, Nomura S, Yamaguchi A, Sasaki K, Deguchi K, Shimizu Y, Bronson R, Gao Y, Inada M, Sato M, Okamoto R, Kitamura Y, Yoshiki S, Kishimoto T. Targeted disruption of Cbfa1 results in a complete lack of bone formation owing to maturational arrest of osteoblasts. Cell. 1997;89:755-64.

24. Nakashima K, Zhou X, Kunkel G, Zhang Z, Deng J, Behringer R, de Crombrugghe B. The novel zinc finger-containing transcription factor osterix is required for osteoblast differentiation and bone formation. Cell. 2002;108:17-29.

25. Lee M, Kwon T, Park H, Wozney J, Ryoo H. Bmp-2-induced osterix expression is mediated by Dlx 5 but is independent of Runx2. Biochem Biophys Res Commun. 2003;309:689-94.

26. Liu T, Gao Y, Sakamoto K, Minamizato T, Furukawa K, Tsukazaki T, Shibata Y, Bessho K, Komori T, Yamaguchi A. Bmp-2 promotes differentiation of osteoblasts and chondroblasts in Runx2-deficient cell lines. J Cell Physiol. 2007;211:728-35.

27. Kato S, Kawabata N, Suzuki N, Ohmura M, Takagi M. Bone morphogenetic protein-2 induces the differentiation of a mesenchymal progenitor cell line, Rob-C26, into mature osteoblasts and adipocytes. Life Sci. 2009;84:302-10.

28. Katagiri T, Yamaguchi A, Ikeda T, Yoshiki S, Wozney JM, Rosen V, Wang EA, Tanaka H, Omura S, Suda T. The nonosteogenic mouse pluripotent cell line, $\mathrm{C} 3 \mathrm{~h} 10 \mathrm{t} 1 / 2$, is induced to differentiate into osteoblastic cells by recombinant human bone morphogenetic protein-2. Biochem Biophys Res Commun. 1990; 172:295-9.

29. Katagiri T, Yamaguchi A, Komaki M, Abe E, Takahashi N, Ikeda T, Rosen V, Wozney JM, Fujisawa-Sehara A, Suda T. Bone morphogenetic protein-2 converts the differentiation pathway of C2c12 myoblasts into the osteoblast lineage. J Cell Biol. 1994;127:1755-66. Erratum Appears in J Cell Biol 1995 Feb;128(4):Following 713. 
30. Namiki M, Akiyama S, Katagiri T, Suzuki A, Ueno N, Yamaji N, Rosen V, Wozney JM, Suda T. A kinase domain-truncated type I receptor blocks bone morphogenetic protein-2-induced signal transduction in C2c12 myoblasts. J Biol Chem. 1997;272: 22046-52.

31. Yamaguchi A, Katagiri T, Ikeda T, Wozney JM, Rosen V, Wang EA, Kahn AJ, Suda T, Yoshiki S. Recombinant human bone morphogenetic protein-2 stimulates osteoblastic maturation and inhibits myogenic differentiation in vitro. J Cell Biol. 1991;113: 681-7.

32. Rosen V. Bmp2 signaling in bone development and repair. Cytokine Growth Factor Rev. 2009;20:475-80.

33. Chandler R, Chandler K, McFarland K, Mortlock D. Bmp2 transcription in osteoblast progenitors is regulated by a distant 3 , enhancer located 156.3 kilobases from the promoter. Mol Cell Biol. 2007;27:2934-51.

34. Tsuji K, Bandyopadhyay A, Harfe B, Cox K, Kakar S, Gerstenfeld L, Einhorn T, Tabin C, Rosen V. Bmp2 activity, although dispensable for bone formation, is required for the initiation of fracture healing. Nat Genet. 2006;38:1424-9.

35. Jikko A, Harris S, Chen D, Mendrick D, Damsky C. Collagen integrin receptors regulate early osteoblast differentiation induced by Bmp-2. J Bone Miner Res. 1999;14:1075-83.

36. Lai C, Cheng S. Alphavbeta integrins play an essential role in Bmp-2 induction of osteoblast differentiation. J Bone Miner Res. 2005;20:330-40.

37. Sotobori T, Ueda T, Myoui A, Yoshioka K, Nakasaki M, Yoshikawa $\mathrm{H}$, Itoh K. Bone morphogenetic protein-2 promotes the haptotactic migration of murine osteoblastic and osteosarcoma cells by enhancing incorporation of integrin beta1 into lipid rafts. Exp Cell Res. 2006;312:3927-38.

38. Tamura Y, Takeuchi Y, Suzawa M, Fukumoto S, Kato M, Miyazono $\mathrm{K}$, Fujita T. Focal adhesion kinase activity is required for bone morphogenetic protein-Smad1 signaling and osteoblastic differentiation in murine Mc3t3-E1 cells. J Bone Miner Res. 2001;16: 1772-9.

39. Suzawa M, Tamura Y, Fukumoto S, Miyazono K, Fujita T, Kato S, Takeuchi Y. Stimulation of Smad1 transcriptional activity by ras-extracellular signal-regulated kinase pathway: a possible mechanism for collagen-dependent osteoblastic differentiation. J Bone Miner Res. 2002;17:240-8.

40. Boudriot U, Dersch R, Goetz B, Griss P, Greiner A, Wendorff JH. Elektrogesponnene poly-L-laktid-nanofasern als resorbierbare matrix fur tissue-engineering. Biomedizinische Technik. 2004;49: 242-7.

41. Jena A, Gupta K. Characterization of pore structure of filtration media. Fluid/Particle. 2002;14:227-41.

42. Pittenger MF, Mackay AM, Beck SC, Jaiswal RK, Douglas R, Mosca JD, Moorman MA, Simonetti DW, Craig S, Marshak DR. Multilineage potential of adult human mesenchymal stem cells. Science. 1999;284:143-7.

43. Brendel C, Kuklick L, Hartmann O, Kim TD, Boudriot U, Schwell $\mathrm{D}$, Neubauer A. Distinct gene expression profile of human mesenchymal stem cells in comparison to skin fibroblasts employing cdna microarray analysis of 9600 genes. Gene Expr. $2005 ; 12$ :

$245-57$.

44. Jaiswal N, Haynesworth SE, Caplan AI, Bruder SP. Osteogenic differentiation of purified, culture-expanded human mesenchymal stem cells in vitro. J Cell Biochem. 1997;64:295-312.

45. Fuchs TF, Petersen W, Vordemvenne T, Stange R, Raschke M, Paletta JR. Influence of synovial fluid on human osteoblasts: an in vitro study. Sci World J. 2007;7:2012-20.

46. Frank O, Heim M, Jakob M, Barbero A, Schafer D, Bendik I, Dick W, Heberer M, Martin I. Real-time quantitative Rt-Pcr analysis of human bone marrow stromal cells during osteogenic differentiation in vitro. J Cell Biochem. 2002;85:737-46.

47. Martin I, Jakob M, Schafer D, Dick W, Spagnoli G, Heberer M. Quantitative analysis of gene expression in human articular cartilage from normal and osteoarthritic joints. Osteoarthr Cartil. 2001;9:112-8.

48. Ma Z, Kotaki M, Inai R, Ramakrishna S. Potential of nanofiber matrix as tissue-engineering scaffolds. Tissue Eng. 2005;11: 101-9.

49. Shih YR, Chen CN, Tsai SW, Wang YJ, Lee OK. Growth of mesenchymal stem cells on electrospun type I collagen nanofibers. Stem Cells. 2006;24:2391-7.

50. Kim H-W, Yu H-S, Lee H-H. Nanofibrous matrices of poly(Lactic Acid) and gelatin polymeric blends for the improvement of cellular responses. J Biomed Mater Res Part A. 2008;87A:25-32.

51. Jäger M, Fischer J, Dohrn W, Li X, Ayers DC, Czibere A, Prall WC, Lensing HS, Krauspe R. Dexamethasone modulates Bmp-2 effects on mesenchymal stem cells in vitro. J Orthop Res. 2008;26:1440-8.

52. Zeng J, Hou H, Schaper A, Wendorff JH, Greiner A. Poly-Llactide nanofibers by electrospinning-influence of solution viscosity and electrical conductivity on fiber diameter and fiber morphology. e-polymers. 2003, No 9.

53. Maretschek S, Greiner A, Kissel T. Electrospun biodegradable nanofiber nonwovens for controlled release of proteins. J Controlled Release. 2008;127:180-7.

54. Kim K, Luu YK, Chang C, Fang D, Hsiao BS, Chu B, Hadjiargyrou M. Incorporation and controlled release of a hydrophilic antibiotic using poly(Lactide-Co-Glycolide)-based electrospun nanofibrous scaffolds. J Controlled Release. 2004;98:47-56.

55. Sieron AL, Louneva N, Fertala A. Site-Specific interaction of bone morphogenetic protein 2 with procollagen II. Cytokine. 2002;18:214-21.

56. Reddi AH. Morphogenetic messages are in the extracellular matrix: biotechnology from bench to bedside. Biochem Soc Trans. 2000;28:345-9.

57. Bruder S, Caplan A. Bone regeneration through cellular engineering. San Diego: Academic Press; 2000.

58. Hutmacher DW. Scaffolds in tissue engineering bone and cartilage. Biomaterials. 2000;21:2529-43. 